\title{
An evaluation of gentamicin EMIT-its performance on the Kem-O-Mat and its role in the small laboratory
}

\author{
RG MASTERTON,${ }^{*}$ RE TETTMAR, PW STRIKE, S WILLIAMS \\ From the Royal Air Force Institute of Pathology and Tropical Medicine, Halton, Aylesbury, \\ Buckinghamshire and ${ }^{*}$ Royal Air Force Hospital Wegberg, BFPO 40.(West Germany)
}

SUMMARY An investigation was made into the use of gentamicin EMIT on the Coulter Kem-OMat in a small microbiology laboratory. EMIT was found to correlate well with plate assay and to be a more rapid, more precise and technically less time-consuming method. EMIT was more expensive in clinical use. This single disadvantage was considered to be outweighed by a saving in capital equipment expenditure and by the benefits to the laboratory and clinician.

The use of gentamicin is complicated by the need to monitor serum concentrations to ensure therapeutic dosage and to avoid toxic side effects. ${ }^{1}$ For many years assay by plate diffusion has been the commonest method. That this technique is not ideal can best be judged by the fact that since 1970 at least 14 further assay methods have been produced. ${ }^{2-5}$ From 1978 an EMIT (enzyme multiplied immunoassay technique, Syva Corp, Palo Alto, Calif) kit has been available. Several method comparison studies involving EMIT have already been published. These have all been performed in large centres and in each case expensive dedicated equipment has been used. $^{6-11}$ It was therefore decided to evaluate this method in a small microbiology laboratory performing the assay on a Coulter Kem-O-Mat.

\section{Material and methods}

\section{SPECIMENS}

A total of 163 peak and trough specimens were assayed in parallel using gentamicin EMIT and microbiological assay. Of these, 62 specimens were from our own hospital and were processed on arrival in the department. The remainder were clinical specimens from two neighbouring hospitals. These were stored at $-20^{\circ} \mathrm{C}^{7}$ and were processed in batches.

INTERNAL QUALITY CONTROL

High and low commercial control samples

Accepted for publication 13 June 1983
(Diamond Diagnostics Ltd) were included in each plate assay and in each EMIT batch.

\section{PLATE ASSA Y}

A standard plate diffusion technique was used. ${ }^{12}$ Plates $\left(100 \mathrm{~mm}^{2}\right)$ containing $30 \mathrm{ml}$ of Oxoid Diagnostic Sensitivity Test Agar (CM 261) were seeded with Klebsiella edwardsii var atlantae NCTC 10896. Every test assay was performed in duplicate, using separate plates, each plate being calibrated with five standard dilutions. A maximum of two test specimens were processed on each plate along with the control samples.

A test result is defined as the mean value from two independent plate assays. All clinical specimens were pretreated with cephalosporinase (Miles Laboratories) in the manner recommended by Selwyn and Bakhtiar. ${ }^{13}$ Growth inhibition was measured on a Dynatech diffusion zone reader and plotted on semilogarithmic graph paper. To compensate for the cephalosporinase dilution the results were multiplied by $1 \cdot 1$.

\section{ENZYME IMMUNOASSAY}

The EMIT assay was performed using the method developed by Coulter Electronics Ltd for the Kem-O-Mat in conjunction with their commercially available tape. The resultant print-out was used to construct a standard curve by subtracting the optical density obtained for the blank $\left(\Delta \mathrm{A}_{0}\right)$ from that obtained for the gentamicin standards $1,2,4,8$ and $16 \mu \mathrm{g} / \mathrm{ml}(\Delta \mathrm{A})$. The values were then plotted on the graph paper supplied with the kit. The standards and 
samples were assayed only once. The test sample result was obtained by referring the corrected test optical density $\left(\Delta A-\Delta A_{o}\right)$ to the standard curve.

\section{METHOD ANALYSIS}

A single technician did all the work. A time and motion study was performed on each technique using the clinical samples from our own hospital.

\section{Results}

\section{RELATIVE BIAS STUDY}

Since they could not be ascribed exact values, the 45 clinical specimens which gave gentamicin concentrations, by either method, of less than $1.5 \mu \mathrm{g} / \mathrm{ml}$ were excluded from the bias study.

The assay comparison study was modelled as a linear structural errors-in-variables relation:

$\mathrm{y}_{\mathrm{i}}=\alpha+\beta . \mathrm{x}_{\mathrm{i}}+\left(\epsilon_{\mathrm{i}}-\beta . \delta_{\mathrm{i}}\right)$

for which the terms $\eta$ and $\xi$ represent the true analyte values underlying the observed test values $x$ (microbiological assay) and y (EMIT assay) respectively:

$$
\begin{aligned}
\mathrm{x}_{\mathrm{i}} & =\xi_{\mathrm{i}}+\delta_{\mathrm{i}} \\
\mathrm{y}_{\mathrm{i}} & =\eta_{\mathrm{i}}+\epsilon_{\mathrm{i}} \\
\text { and } \eta_{\mathrm{i}} & =\alpha+\beta . \xi_{\mathrm{i}}
\end{aligned}
$$

The terms $\delta$ and $\epsilon$ represent the random error terms in the microbiological and EMIT assays respectively, with variances $\sigma_{\delta}^{2}$ and $\sigma_{\epsilon}^{2}$, the errors being assumed independent Normal. The parameters $\alpha$ and $\beta$ represent the analytical biases between

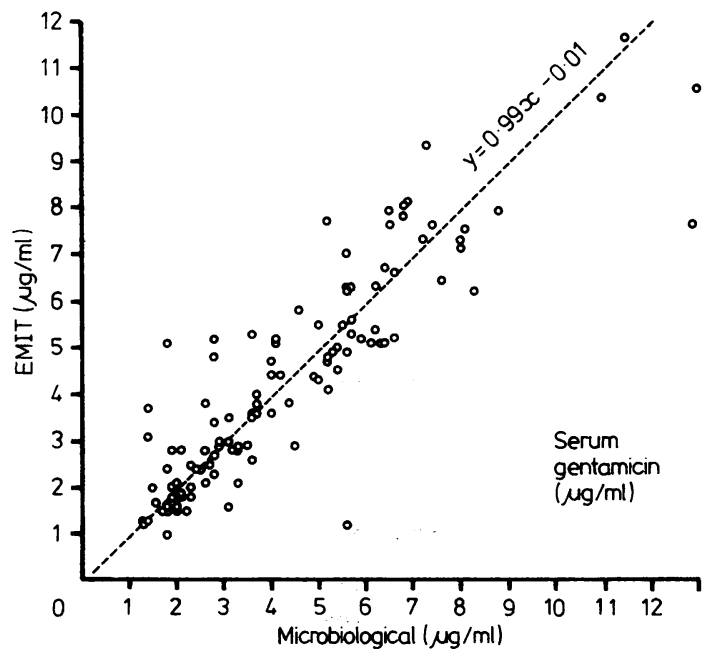

Fig. 1 Serum gentamicin assay method comparison data. 115 test sera assayed by Microbiological $(x)$ and EMIT $(y)$ assay systems. the two assay systems with expected values 0 and 10 respectively in the absence of such bias. Estimates of these parameters were obtained using the maximum likelihood estimators with the variance ratio $\lambda=\vec{F}$ $\sigma_{\epsilon}^{2} / \sigma_{\delta}^{2}$ known, ${ }^{14}$ an estimate of $\lambda$ being obtained from independent replication studies. Although the error $\frac{\mathrm{C}}{\mathrm{O}}$ variances are non-constant throughout the concentration range of each assay system, their ratio was considered sufficiently stable to justify the estimation procedure used. The estimated relationship was $\infty$ $\mathrm{y}=0.99 \mathrm{x}-0.01$ (Fig. 1).

No significant difference $(p>0 \cdot 1)$ was detected between these estimates and the parameter values $\vec{\omega}$ expected under the hypothesis of no analytic bias. This indicates a high degree of correspondence bet-? ween the expected values of the two assay systems.

For the observed test values this underlying cor- $\overrightarrow{-}$ respondence is overlaid by the purely random meas- $\vec{N}$ urement errors inherent in both assay systems giving $A$ rise to the scatter seen in Fig. 1 (correlation coefficient $0 \cdot 873$ ).

\section{BETWEEN BATCH IMPRECISION STUDIES}

Ten quality control samples spanning the analyte range $2 \cdot 3-11.1 \mu \mathrm{g} / \mathrm{ml}$ were assayed a minimum of $\frac{0}{\circ}$ six times over a six-month period by each assay $\stackrel{\mathbb{C}}{-}$ method.

For each control sample the standard deviation $\frac{0}{90}$ the assay values has been plotted against the corred ponding mean gentamicin value, the relationsh between these two variables for the entire control sample set being approximated by a quadratic polynomial (Fig. 2). The procedure permits a simple $\frac{\circ}{\mathbb{D}}$ assessment of the relative imprecision of the two assay systems across the range of gentamicin con- 0 centration studied. The EMIT assay system exhibits a lower level of imprecision than the microbiological assay, particularly for gentamicin concentration in excess of $5 \mu \mathrm{g} / \mathrm{ml}$.

\section{CALIBRATOR RESPONSE STABILITY}

The calibrator response stability was determined by analysis of the standard curves obtained from each $₹$ EMIT run. The range of variation in the calibratoro responses for the EMIT assay system is described in Fig. 3 for two production Lots of the assay kit, each음 Lot being assayed over a three-month period. The response variation within production Lots is consid-or erable, particularly for high analyte concentrations. $N$

Six calibrators is the absolute minimum required for calibrating the non-linear response function associated with the EMIT assay system on the Kem-O-Mat.

TIME AND COST STUDY

The results of the method analysis are shown in 


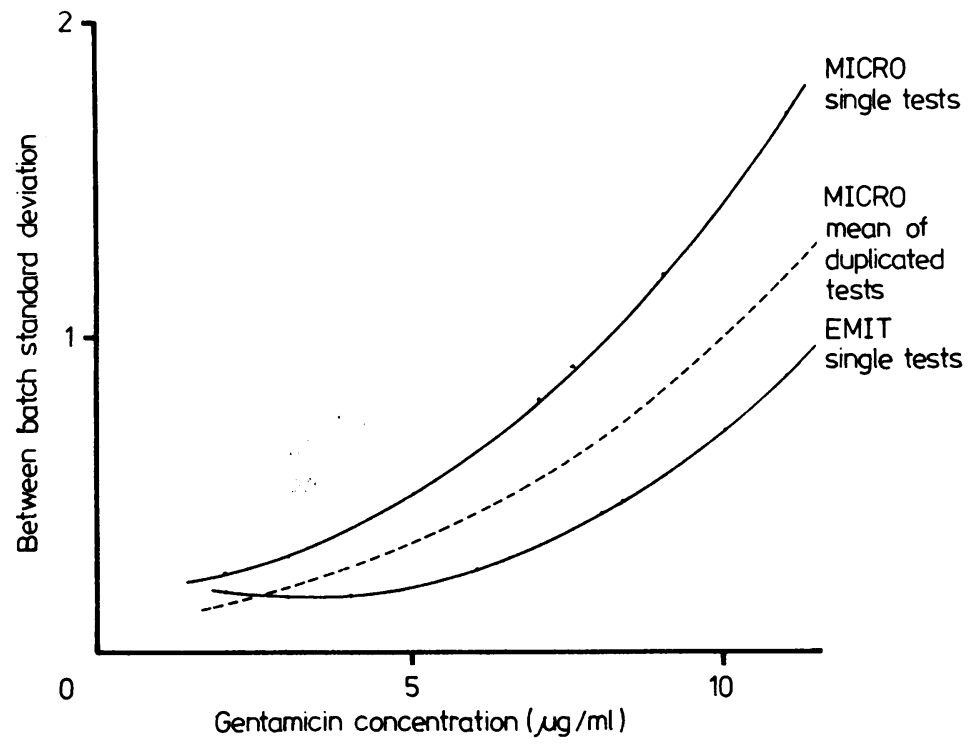

Fig. 2 Precision profiles for Microbiological and EMIT gentamicin assay systems. Data obtained at $\times 10$ concentration levels for each assay system. Profiles approximated by quadratic polynomials.
Table 1. The cost does not include technician time or capital equipment outlay but does take into consideration the price of the kit, standards, control specimens and all disposables. The cost for EMIT is based on running one peak and one trough for each standard curve and two control specimens. This figure drops substantially when more samples are assayed with each standard curve until at 10 specimens the cost is $£ 1.60$ per unit.

The turn-round time was the period between receipt of specimen at the laboratory and the arrival of the result at the ward. In the case of plate assay this was extremely variable with a range from $4 \frac{1}{2-}$ $20 \mathrm{~h}$ depending upon the time of the day that the specimen arrived.

The technician times reflect the net time involved in each assay and do not include waiting periods. The times for EMIT are based on running one peak and trough per standard curve. When processed in batches each additional EMIT specimen represents a further two minutes work. In comparison the plate assay shows little reduction in time for performing

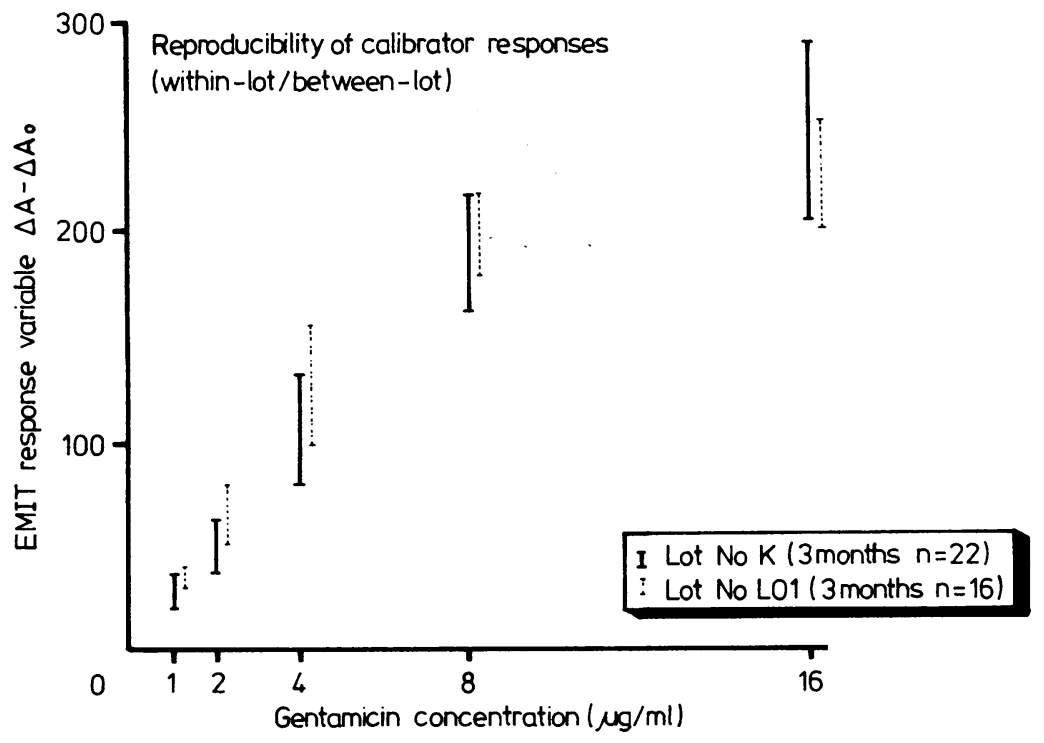

Fig. 3 EMIT calibrator response stability over three month period: within and between commercial production batches. 
Table 1 Time and cost study

\begin{tabular}{llc}
\hline & EMIT & Plate assay \\
\hline *Cost per specimen & $£ 5$ & $80 \mathrm{p}$ \\
+Average specimen turn round & $30 \mathrm{~min}$ & $7 \mathrm{~h}$ \\
time & $10 \mathrm{~min}$ & $50 \mathrm{~min}$ \\
\hline
\end{tabular}

*To nearest 10 pence.

†To nearest $5 \mathrm{~min}$.

multiple samples since the majority of the $50 \mathrm{~min}$ is taken up by preparing and reading the two diffusion plates used for each sample pair.

\section{Discussion}

For nearly 40 years plate diffusion methods have been used to assay antimicrobial drugs. ${ }^{15}$ Although, in the case of gentamicin, this method is reported as being capable of acceptable levels of reliability and accuracy, ${ }^{5}$ practical disadvantages include a lack of reproducibility, interference from other agents and a minimum time delay of three hours. ${ }^{21617}$ Using the criteria of the United Kingdom National Quality Control of Serum Aminoglycoside Assays ${ }^{18}$ the performance of the Gram negative plate assay method has improved considerably over the last 10 years. Whereas in 1974 only $50 \%$ of laboratories using this method produced acceptable results, ${ }^{19}$ by 1981 this figure had risen to approximately $79 \%,{ }^{18}$ although less than $40 \%$ were judged ideal in the clinical situation. The experience in 1982 is similar (LO White, personal communication 1983).

Many workers have therefore tried to produce a better alternative method. One of these was the introduction of an enzyme multiplied immunoassay technique for gentamicin. EMIT has been reported by several authors to be accurate, precise, simple to perform, rapid, specific and interchangeable with plate assay in terms of its correlation coefficient. ${ }^{6-11}$ It is also comparatively free from interference with both exogenous and endogenous substances. ${ }^{7-11} 2021$ It may be a reflection of these features that the number of laboratories returning National Quality Control results and using the EMIT method have increased from less than $1 \%$ in $1978^{18}$ to $21 \%$ in 1982 (LO White, personal communication 1983). Certainly experience with EMIT in the National Quality Control scheme has shown that this is the most accurate and precise method currently in use. ${ }^{18}$

However one of its disadvantages is the need for expensive equipment. Recommended instruments for performing EMIT cost in excess of $£ 4500$. To small laboratories such as our own wishing to improve on plate assay results, this represents a perhaps unjustifiable capital expenditure. Although not actively promoted as such, EMIT can be performed on the Kem-O-Mat, a discrete analyser found in many biochemistry departments. The Kem-O-Mat for our study was made available for our use by the neighbouring biochemistry department and by this sharing of existing equipment the only cost to our department in establishing the EMIT method was $£ 40$, for the Coulter tape. As far as we are aware this is the first published method comparison involving gentamicin EMIT utilising the Kem-O-Mat.

From the work of Selepak et al ${ }^{10}$ it was obvious from the start of our study that cost would be a major factor in assessing the suitability of the Kem-O-Mat/EMIT combination in the small laboratory. Every effort was therefore made to minimise expenditure and to this end EMIT assays were not performed in duplicate. The manufacturer recommends that the blank control and clinical specimens should be assayed in duplicate and previous workers have followed these recommendations.

Whilst our regression study reveals no systematic bias between the results obtained from the microbiological and EMIT assay systems, in keeping with previous reports, ${ }^{6-11}$ the degree of correspondence between individual test results from both assay methods is relatively poor as a direct result of the imprecision inherent in both assay systems. Ou imprecision studies clearly identify the microbiolog ical assay as substantially more imprecise than the EMIT assay for gentamicin concentrations in excess of approx $3 \mu \mathrm{g} / \mathrm{ml}$ (Fig. 2), thus accounting for the greater proportion of the scatter evident in our relative bias study (Fig. 1). We can further state that on the criterion of expected imprecision alone, the non-replicated EMIT assay is clearly more acceptable for routine clinical use.

Moreover, we have shown that the Kem-O-Mat/ EMIT combination produced a valuable saving both in technician time and in specimen turn-round time (Table 1).

A feature of the manufacturer's recommended equipment is that a standard curve once obtained can be used for several runs with a resultant saving in time and cost per specimen. This is of particular value when handling a heavy volume of work. Many small laboratories would not be able to take full advantage of this standard curve stability since they deal with small runs of specimens widely spaced in time. Certainly our calibrator studies showed that each Kem-O-Mat/EMIT run must have its own set of standards with a minimum of six calibrators including the blank.

Kem-O-Mat/EMIT cost per specimen is $\stackrel{\oplus}{\rightarrow}$ significantly greater than plate assay. However, as our laboratory processes only a small number of 
clinical specimens the total increase in annual expenditure is negligible in terms of the department budget. In our opinion this single economic disadvantage is outweighed by the improvements gained to the laboratory and clinical service. We therefore feel that, where equipment sharing is feasible, small microbiology laboratories wishing to improve on plate assay may profitably consider gentamicin EMIT on the Kem-O-Mat.

We are grateful to the Director General of Medical Services, Royal Air Force, for permission to publish this paper.

We are indebted to Dr AP Gillet, Consultant Microbiologist, Stoke Mandeville Hospital and Mr HM Meddick, Senior Chief MLSO, Oxford Public Health Laboratory, for their kind donation of clinical samples.

\section{References}

' Kucers A, Bennett NMcK. The use of antibiotics. London: William Heinemann, 1979;325-58.

${ }^{2}$ Maitra SK, Yoshikawa TT, Guze LB, Schotz MC. Determination of aminoglycoside antibiotics in biological fluids: a review. Clin Chem 1979;25:1361-7.

${ }^{3}$ Nilsson L. New rapid bioassay of gentamicin based on luciferase assay of extracellular ATP in bacterial cultures. Antimicrob Agents Chemother 1978;14:812-6.

4 Urban T, Jarstand C. Rapid micromethod for aminoglycoside assays in serum by utilization of bacterial reduction by nitroblue tetrazolium. J Antimicrob Chemother 1980;6:357-61.

s Phillips I, Warren C, Smith SE. Serum gentamicin assay: a comparison and assessment of different methods. J Clin Pathol 1974;27:447-51.

- Chinwah P, Williams K. Comparison of enzyme immunoassay for gentamicin compared with other methods. J Antimicrob Chemother 1980;6:561-2.

' O'Leary TD, Ratcliff RM, Geary TD. Evaluation of an enzyme immunoassay for serum gentamicin. Antimicrob Agents Chemother 1980;17776-8.

${ }^{8}$ Phaneuf D, Francke E, Neu HC. Rapid, Reproducible enzyme immunoassay for gentamicin. J Clin Microbiol 1980;11:2669.

9 Dols JLS, Van Zanten AP. Gentamicin assay: comparison of an adapted EMIT method and an RIA method. Ann Clin Biochem 1981;18:236-9.

${ }^{10}$ Selepak ST, Witebsky FG, Robertson EA, MacLowry JD. Evaluation of five gentamicin assay procedures for clinical microbiology laboratories. J Clin Microbiol 1981;13:742-9.

"White LO, Scammell LM, Reeves DS. Serum aminoglycoside assay by enzyme-mediated immunoassay (EMIT): Correlation with radioimmunoassay, fluoroimmunoassay, and acetyltransferase and microbiological assays. Antimicrob Agents Chemother 1981;19:1064-6.

12 Garrod LP, Lambert HP, O'Grady F. Antibiotic and chemotherapy 5th ed. Edinburgh: Churchill-Livingstone, 1981:496-501.

${ }^{13}$ Selwyn S, Bakhtiar M. Inactivation of cephalosporins in blood cultures and mixed assays with a commercially available enterobacter $\beta$-lactamase. $J$ Antimicrob Chemother 1979;5:318-9.

14 Strike PW. Medical laboratory statistics. Bristol: Wright, 1981:173-89.

${ }^{15}$ Fleming A. Streptococcal meningitis treated with penicillin measurement of bacteriostatic power of blood and cerebrospinal fluid. Lancet 1943;ii:434.

${ }^{16}$ Shanson DC, Hince C. Serum gentamicin assay of 100 clinical serum samples by a rapid $40^{\circ} \mathrm{C}$ Klebsiella method compared with overnight plate diffusion and acetyltransferase assays. $J$ Clin Pathol 1977;30:521-5.

${ }^{17}$ de Louvois J. Factor influencing the assay of antimicrobial drugs in clinical samples by the agar plate diffusion method. $J$ Antimicrob Chemother 1982;9:253-65.

${ }^{18}$ Bywater MJ, Holt HA, Reeves DS. Current chemotherapy and immunotherapy-Proc 12th I.C.C. Vol II. 1982:795-7.

${ }^{19}$ Reeves DS, Bywater MJ. Quality control of serum gentamicin assays-experience of national surveys. J Antimicrob Chemother 1975;1:103-16.

${ }^{20}$ Emit -and TM Gentamicin Assay (package insert). Syva, Palo Alto Ca 94303, 1981:23-5.

${ }^{21}$ Knight D, Ukena T. Heparin does not affect enzyme immunoassay of gentamicin. Clin Chem 1981;27:640.

Requests for reprints to: Dr RE Tettmar, Consultant Microbiologist, RAF Institute of Pathology and Tropical Medicine, Halton, Aylesbury, Bucks HP22 5PG, England. 